Journal of

Molecular Microbiology

and Biotechnology

\title{
Optimization of a Heterologous Signal Peptide by Site-Directed Mutagenesis for Improved Secretion of Recombinant Proteins in Escherichia coli
}

\author{
Mohd Anuar Jonet $^{\mathrm{a}} \quad$ Nor Muhammad Mahadi $^{\mathrm{b}} \quad$ Abdul Munir Abdul Murad ${ }^{\mathrm{c}}$ \\ Amir Rabuc Farah Diba Abu Bakarc Raha Abdul Rahim ${ }^{c}$ Kheng Oon Low ${ }^{\text {a }}$ \\ Rosli Md. Illias ${ }^{a}$ \\ a Department of Bioprocess Engineering, Faculty of Chemical Engineering, Universiti Teknologi Malaysia, Skudai, \\ ${ }^{b}$ Malaysia Genome Institute, Ministry of Science, Technology and Innovation, Kajang, 'School of Biosciences and \\ Biotechnology, Faculty of Science and Technology, Universiti Kebangsaan Malaysia, Bangi, and d Department \\ of Cell and Molecular Biology, Faculty of Biotechnology and Biomolecular Sciences, Universiti Putra Malaysia, \\ Serdang, Malaysia
}

\section{Key Words}

Cyclodextrin glucanotransferase $\cdot$ Secretion $\cdot$ Heterologous signal peptide $\cdot$ Site-directed mutagenesis $\cdot$ Escherichia coli

\begin{abstract}
A heterologous signal peptide (SP) from Bacillus sp. G1 was optimized for secretion of recombinant cyclodextrin glucanotransferase (CGTase) to the periplasmic and, eventually, extracellular space of Escherichia coli. Eight mutant SPs were constructed using site-directed mutagenesis to improve the secretion of recombinant CGTase. M5 is a mutated SP in which replacement of an isoleucine residue in the h-region to glycine created a helix-breaking or G-turn motif with decreased hydrophobicity. The mutant SP resulted in 110 and 94\% increases in periplasmic and extracellular recombinant CGTase, respectively, compared to the wild-type SP at a similar level of cell lysis. The formation of intracellular inclusion bodies was also reduced, as determined by sodium dodecyl sulfate-polyacrylamyde gel electrophoresis, when this mutated SP was used. The addition of as low as $0.08 \%$ glycine at
\end{abstract}

the beginning of cell growth improved cell viability of the E. coli host. Secretory production of other proteins, such as mannosidase, also showed similar improvement, as demonstrated by CGTase production, suggesting that the combination of an optimized SP and a suitable chemical additive leads to significant improvements of extracellular recombinant protein production and cell viability. These findings will be valuable for the extracellular production of recombinant proteins in E. coli.

Copyright $\odot 2012$ S. Karger AG, Basel

\section{Introduction}

For the last decade, the understanding of the mechanism of bacterial protein translocation has enabled researchers to devise better strategies to enhance the efficiency of extracellular heterologous protein production. The Bacillus subtilis expression system is usually used to achieve hypersecretion of target proteins at high concentrations. However, the system suffers from the endoge-

\section{KARGER}

Fax +4161306 1234

E-Mail karger@karger.ch

www.karger.com
(C) 2012 S. Karger AG, Basel

$1464-1801 / 12 / 0221-0048 \$ 38.00 / 0$

Accessible online at:

www.karger.com $/ \mathrm{mmb}$
Rosli Md. Illias

Department of Bioprocess Engineering

Faculty of Chemical Engineering, Universiti Teknologi Malaysia

Skudai, Johor 81310 (Malaysia)

Tel. +60 7553 5804, E-Mail r-rosli@utm.my 
nous extracellular proteases that may lower the protein production yield due to degradation [Nakamura et al., 1985]. Alternatively, an Escherichia coli expression system is an attractive choice. This is exemplified by several exciting findings that show high levels of extracellular secretion of recombinant proteins in E. coli despite normal cytoplasmic expression [Sanchez et al., 1999]. Although cytoplasmic expression is widely accepted, recombinant proteins are often found as inclusion bodies. In addition, problems such as protease degradation and complicated downstream purification lead to reduced final protein yield. Targeting the recombinant proteins to the periplasmic or the extracellular space can, to a certain extent, effectively mitigate the above problems. Importantly, the periplasmic and extracellular spaces are relatively oxidative environments and contain fewer host proteins than the cytoplasmic space, thus enabling proteins to correctly fold and be easily purified to homogeneity due to less contamination of endogenous proteins.

However, E. coli naturally does not secrete proteins into the extracellular medium under standard laboratory conditions [Pugsley and Francetic, 1998]. Thus, extracellular secretion in E. coli always correlates with non-specific leakage and cell lysis [Ni and Chen, 2009; Shokri et al., 2002], which could be due to pressure build-up in the periplasmic space. While a higher protein translocation rate is preferable, it can have lethal effects on the host cell [Fu et al., 2005].

A number of strategies have been developed to produce secreted proteins in E. coli. These strategies include the use of leaky strains, such as the wall-less strain, the Lform strain and the lpp deletion strain; co-expression of lysis-promoting proteins, such as the kill protein or the bacteriocin release protein; co-expression of proteins that assist translocation and folding; co-expression of proteins involved in the secretory pathways, and, finally, selection and modification of signal peptides [Yoon et al., 2010]. Before the proteins are released to the extracellular space, target proteins are usually exported from the cytoplasm to the periplasm by fusion with the correct signal peptide (SP) or carrier protein [Fu, 2010]. The use of heterologous SPs from Bacillus spp. yields secretion of proteins to the periplasmic space and finally to the extracellular space when expressed in E. coli [Jeong and Lee, 2000; Yamabhai et al., 2008]. Even though the structures of the cell membrane and cell wall of E. coli and Bacillus sp. are significantly different, several lines of evidence suggest that the molecular mechanisms of protein export in both types of bacteria are related and share a number of similar features, including the use of a SP. Far less is known regard- ing the roles of signal sequences in protein trafficking in Gram-positive bacteria and, in particular, their behavior or function in E. coli systems [Bensing et al., 2007]. The SPs of Gram-positive organisms overall are slightly more hydrophobic than those of Gram-negative organisms. Although the primary amino acid sequences of SPs are not conserved [von Heijne and Abrahmsen, 1989], they share certain common features. Generally, three distinct regions can be found in a typical SP: (i) an N-terminal region (n-region) that contains a number of positively charged amino acids (lysines and arginines); (ii) a central hydrophobic core region (h-region), and (iii) a hydrophilic cleavage region (c-region) that contains a sequence motif recognized and cleaved by signal peptidases. Mutations in SPs affect target protein secretion. Replacement of $\mathrm{N}$-terminal positively charged amino acids results in decreased secretion efficiency and impaired interaction with anionic phospholipids [Nesmeyanova et al., 1997]. In addition, the n-region affects the functions of SPs as intramolecular chaperones and, in cooperation with SecA and $\operatorname{Sec} B$, as factors of premature protein targeting to the membrane [Khokhlova and Nesmeyanova, 2003]. Moreover, substitutions of hydrophobic residues for polar residues in the h-region accelerate processing of the precursor to the mature form and increase the level of secretion [Morioka-Fujimoto et al., 1991]. Furthermore, substitution of residues in the c-region with polar and small amino acids increases premature protein processing and efficiency in protein transport [Morioka-Fujimoto et al., 1991]. However, the effects of mutations in all regions of heterologous SPs, particularly from Bacillus sp., on protein secretion in E. coli have not been previously addressed.

Cyclodextrin glucanotransferase (CGTase) is an industrially important enzyme that produces cyclodextrin when CGTase reacts with starch. Previously, we have shown that CGTase from Bacillus sp. G1 fuses with its native SP, leading to secretion of the enzyme to the extracellular space of the host E. coli [Ong et al., 2008]. In this work, we describe mutations to optimize and improve secretion of the CGTase and the effects of these mutations on cell viability. We also describe the use of additives to reduce cell lysis due to the secretion.

\section{Materials and Methods}

E. coli Strains and Growth Conditions

E. coli strain JM109 [recA, endA1, gyrA96, thi, hsdR17, supE44, relA1, $\Delta\left(\right.$ lac-proAB)/F' $\left(\right.$ traD36, proAB ${ }^{+}$, lacI ${ }^{\mathrm{q}}$, lac $\left.\left.\Delta \mathrm{M} 15\right)\right]$ and $E$. coli BL21(DE3) [E. coli F-ompT hsdSB (rB- mB-) gal dcm (DE3)] were chosen to be the hosts for the cloning and expression of the 
Table 1. Oligonucleotides used in this study

\begin{tabular}{ll}
\hline Primer & Sequence \\
\hline FSG1 NdeI & 5' GCCCATATGAACGATTTAAATGATTTT 3' \\
Rvs SG1 BamHI & 5' GCCGGATCCAGCCTCCGCAACACTAGG 3' \\
FwdK NdeI & 5' GCCCATATGAAGGATTTAAATGATTTT 3' \\
FwdKK NdeI & 5' GCCCATATGAAGAAGTTAAATGATTTT 3' \\
Rvs S BamHI & 5' GCCGGATCCAGCCTCGGAAACAGTAGGTAA 3' \\
Rvs G BamHI & 5' GCCGGATCCAGCCTCAACACTAGG 3' \\
F16IleGly & 5' GCCCATATGAACGATTTAAATGATTTTTTGAAAACGATTTCATTAAGCTTTGGCTTT 3' \\
F14SerGly & 5' GCCCATATGAACGATTTAAATGATTTTTTGAAAACGATTTCATTAGGCTTTATCTTT 3' \\
F14SerLeu & 5' GCCCATATGAACGATTTAAATGATTTTTGAAAACGATTTCATTACTCTTTATCTTT 3' \\
R18PheGly & 5' GCCGGATCCAGCCTCCGCAACAGTAGGTAAAGAAAGAAGCAAGCCAAAGAT 3' \\
FMANOEcoRI & 5' ATATGAATTCCAGGCTGGTCCTTGGGCC 3' \\
RMANONotI & 5' GGCCGCGGCCGCGTTCTTGTTGACATTTTCCA 3' \\
\hline
\end{tabular}

Table 2. Primer combinations used for genetic constructs

\begin{tabular}{|c|c|c|}
\hline \multirow{2}{*}{$\begin{array}{l}\text { Signal peptide } \\
\text { (SP) }\end{array}$} & \multicolumn{2}{|l|}{ Primers } \\
\hline & forward & reverse \\
\hline G1 & FSG1 NdeI & Rvs SG1 BamHI \\
\hline BM1 & FwdK NdeI & Rvs SG1 BamHI \\
\hline BM9 & F14SerLeu & Rvs SG1 BamHI \\
\hline BM7 & F14SerGly & Rvs SG1 BamHI \\
\hline BM11 & FSG1 NdeI & R18PheGly \\
\hline BM5 & F16IleGly & Rvs SG1 BamHI \\
\hline $\mathrm{BM} 2$ & FSG1 NdeI & Rvs S BamHI \\
\hline BM4 & FSG1 NdeI & Rvs G BamHI \\
\hline
\end{tabular}

constructed plasmids in this study. pET systems from Novagen were used as the vector backbones for cloning the wild-type SP and its variants fused to the CGTase gene. Recombinant cells were cultured in Luria-Bertani (LB) medium supplemented with $50 \mu \mathrm{g} / \mathrm{ml}$ ampicillin at $37^{\circ} \mathrm{C}$ and $12,100 \mathrm{~g}$, unless stated otherwise.

\section{Construction of Expression Plasmids}

DNA fragments encoding the CGTase gene cloned into plasmid pET21a(+) and designated as BSC21 and its derivatives were amplified by PCR using plasmids containing the CGTase gene as template [Ong et al., 2008]. Amplification of DNA was performed under standard PCR conditions in a 50- $\mu$ l reaction volume with 1 pmol of each primer, $1 \mathrm{U}$ of KOD Hotstart polymerase (Novagen), and $100 \mathrm{ng}$ of template DNA. Amplified SPs were purified after gel electrophoresis using the Qiaex II gel extraction kit (Qiagen, Germany) and digested with NdeI and BamHI before ligation into plasmid CGT21 (digested plasmid pET21a carrying CGTase gene). The resulting plasmids contained the amplified SP fragments upstream of the Bacillus sp. G1 CGTase gene from which the wild-type SP was deleted. Oligonucleotides used as primers in the PCRs are shown in table 1 . The combinations of primers used to construct the plasmids are shown in table 2. Plasmids were propagated in E. coli JM109, and sequences of all SP derivatives were confirmed by sequencing both strands. To study expression levels, plasmids were subsequently introduced into E. coli BL21 (DE3). The DNA fragment encoding Aspergillus flavus endomannosidase cDNA was amplified by PCR using primers FMANOEcoRI and RMANONotI from a laboratory clone. The resulting 1,329-bp DNA fragment was end-digested with BamHI and Not I before ligation into the corresponding site of BS21 (plasmid containing G1 SP) and BM5 (plasmid containing M5 SP), yielding BSM and BM5M, respectively.

\section{CGTase Expression in Recombinant E. coli}

Recombinant $E$. coli harboring the appropriate expression plasmids were inoculated into $5 \mathrm{ml}$ of LB broth containing $50 \mu \mathrm{g} /$ $\mathrm{ml}$ of ampicillin and incubated at $37^{\circ} \mathrm{C}$ for $16 \mathrm{~h}$. Two milliliters of the overnight culture was inoculated into $50 \mathrm{ml}$ of LB broth containing $50 \mu \mathrm{g} / \mathrm{ml}$ ampicillin and grown at $37^{\circ} \mathrm{C}$ until $\mathrm{OD}_{600 \mathrm{~nm}}$ reached 0.8. Recombinant gene expression was induced by addition of $0.01 \mathrm{~mm}$ isopropyl- $\beta$-D-thiogalactopyranoside (IPTG) and further incubation at $30^{\circ} \mathrm{C}$ for $24 \mathrm{~h}$. Samples were collected at different time points post-induction to determine the profile of extracellular protein expression.

\section{Cell Fractionation}

Medium Fractionation. Five milliliters of culture was harvested, and the cells were pelleted by centrifugation at $10,000 \mathrm{~g}$ at $4^{\circ} \mathrm{C}$ for $10 \mathrm{~min}$. The supernatant fraction was collected. The cell pellet was re-suspended in $2.5 \mathrm{ml} 30 \mathrm{~mm}$ Tris- $\mathrm{HCl}, \mathrm{pH} 8.0$ with $20 \%$ sucrose, and EDTA was added to a final concentration of $1 \mathrm{~mm}$. The cell suspension was incubated at room temperature for $10 \mathrm{~min}$ and pelleted by centrifugation at $10,000 \mathrm{~g}$ at $4^{\circ} \mathrm{C}$ for $10 \mathrm{~min}$. The supernatant was collected into periplasmic tube collectors, and the cells were resuspended in $2.5 \mathrm{ml}$ ice-cold $5 \mathrm{mM} \mathrm{MgSO}_{4}$ before incubation on ice for $10 \mathrm{~min}$. The cells were pelleted by centrifugation as above, and the supernatant was kept with the first periplasmic sample to obtain a total periplasmic fraction. The pellet was re-suspended in $5 \mathrm{ml} \mathrm{PBS}$ and sonicated, and the supernatant was col- 
Table 3. Effects of promoter on CGTase production and localization in recombinant E. coli

\begin{tabular}{lllll}
\hline \multirow{2}{*}{ Promoter } & \multicolumn{2}{l}{ CGTase activity, U/ml } & \multirow{2}{*}{ Reference } \\
\cline { 2 - 3 } & extracellular & periplasm & cytoplasm & \\
\hline Bacillus sp. G1 wild-type promoter $^{\mathrm{a}}$ & 35.71 & 14.00 & 7.63 & $\begin{array}{l}\text { Ong et al., 2008 } \\
\text { T7lac }^{b}\end{array}$ \\
\hline
\end{tabular}

${ }^{\text {a }}$ CGTase activity measured after $24 \mathrm{~h}$ cultivation.

${ }^{\mathrm{b}}$ CGTase activity measured at $12 \mathrm{~h}$ post-induction.

lected as a cytoplasmic fraction. Each fraction was analyzed using sodium dodecyl sulfate-polyacrylamide gel electrophoresis (SDSPAGE) followed by Western blot or enzymatic activity assays.

\section{Enzyme Assay for CGTase and Protein Analysis}

One milliliter of substrate buffer containing $40 \mathrm{mg} / \mathrm{ml}$ soluble starch in $0.1 \mathrm{M}$ phosphate buffer, $\mathrm{pH} 6.0$, was added to $0.1 \mathrm{ml}$ protein sample and incubated at $60^{\circ} \mathrm{C}$ for $10 \mathrm{~min}$. The reaction was terminated by addition of $3.5 \mathrm{ml}$ of $30 \mathrm{~mm}$ sodium hydroxide. 500 $\mu \mathrm{l}$ of $0.02 \%(\mathrm{w} / \mathrm{v})$ of phenolphthalein in $5 \mathrm{mM}$ sodium carbonate was added to the reaction mixture and incubated for $15 \mathrm{~min}$ at room temperature. The reduction in color intensity was measured at $550 \mathrm{~nm}$. One unit of enzyme activity was defined as the amount of enzyme that formed $1 \mu \mathrm{mol}$ of $\beta$-cyclodextrin per minute under the experimental condition. The soluble and insoluble fractions were analyzed by $10 \%$ SDS-PAGE under reducing conditions [Laemmli, 1970], and by Western blot using mouse monoclonal anti-polyhistidine alkaline phosphatase antibody followed by detecting with an alkaline phosphate substrate (NBT/BCIP).

\section{Enzyme Assay for $\beta$-Mannosidase}

$\beta$-Mannosidase activity was determined with the substrate locust bean gum in $50 \mathrm{~mm}$ sodium phosphate buffer ( $\mathrm{pH}$ 5.7) to a final concentration of $0.5 \%(\mathrm{w} / \mathrm{v})$. Assays were performed by mixing $0.1 \mathrm{ml}$ of an appropriately diluted enzyme with $0.4 \mathrm{ml}$ of the substrate at $40^{\circ} \mathrm{C}$ for $5 \mathrm{~min}$. The reactions were terminated by the addition of $0.5 \mathrm{ml}$ of 3,5-dinitrosalicyclic acid solution and boiled for $10 \mathrm{~min}$ in a water bath. The amount of reducing sugar released was measured at a wavelength of $540 \mathrm{~nm}$. Mannose was used as the standard in the assay. One unit (U) of enzyme activity was defined as the amount of enzyme producing $1 \mu \mathrm{mol}$ of mannose per minute under the same conditions.

\section{Determination of Cell Viability}

Cell viability was quantified by determining the amount of $\beta$ galactosidase in the extracellular medium using $o$-nitrophenyl$\beta$-D-galactopyranoside (ONPG). One milliliter of substrate buffer containing $4.0 \mathrm{mg} / \mathrm{ml}$ ONPG in $0.1 \mathrm{~mm}$ phosphate buffer $(\mathrm{pH}$ 7.4) was added to $0.1 \mathrm{ml}$ of the sample, which was then incubated at $37^{\circ} \mathrm{C}$ for $10 \mathrm{~min}$. The reaction was stopped by addition of 0.5 $\mathrm{ml}$ of $1 \mathrm{M}$ sodium carbonate, and the absorbance was read at 420 $\mathrm{nm}$. One unit of enzyme activity was defined as the amount of enzyme that formed $10^{-8} \mathrm{~mol}$ of ONP per minute under the experimental conditions.

Optimization of a Heterologous Signal

Peptide by Site-Directed Mutagenesis

\section{Accession Numbers}

The nucleotide sequences of the CGTase and mannosidase genes described in this paper have been deposited in the GenBank database (accession numbers AY770576 and JF518979 respectively).

\section{Results and Discussion}

\section{Construction of the Secretory Expression Plasmid}

A gene fragment encoding CGTase containing wildtype SP from Bacillus sp. G1 was amplified using PCR and cloned into the expression plasmid pET21a(+). The constructed plasmid, named BSC21, directed the secretory expression of the enzyme driven by the T7lac promoter and induced by the addition of IPTG. The plasmid was then transformed into E. coli BL21(DE3). CGTase expression by BSC21 was compared to that of a previously developed expression system [Ong et al., 2008] that used the Bacillus sp. G1 promoter and wild-type SP fused to the CGTase gene. The results presented in table 3 show that expression of CGTase to the cytoplasmic, periplasmic and extracellular spaces of the E. coli host harboring expression plasmid BSC21 increased by 1.5-, 5.9- and 3.5fold, respectively, compared to the system of Ong et al. [2008]. Wild-type Bacillus sp. G1 reportedly produces extracellular CGTase at $54.9 \mathrm{U} / \mathrm{ml}$, which is about half that achieved in this study [Ibrahim et al., 2003]. The strong promoter used is believed to promote higher gene expression, enabling a higher synthesis rate of recombinant CGTase and eventually a higher rate of secretion.

\section{Modification of N-Terminal SP for Improved CGTase Secretion}

CGTase is an extracellular enzyme whose secretion into the extracellular space in wild-type Bacillus sp. G1 is driven by a SP. The wild-type SP works well in E. coli, as shown by Ong et al. [2008] and in our construct (BSC21) 
Table 4. Amino acid sequences of the wild-type CGTase SP (G1), its mutants and predicted effect of each mutation

\begin{tabular}{lllll}
\hline SP & n-region & h-region & c-region & Predicted mutation effect \\
\hline G1 & MNDLNDFLK & TISLSFIFFLLL & SLPTVAEA & Wild-type SP \\
M1 & MKDLNDFLK & TISLSFIFFLLL & SLPTVAEA & Increase net charge from -2 to -1 \\
MKK & MKKLNDFLK & TISLSFIFFLLL & SLPTVAEA & Increase net charge from -2 to +1 \\
M9 & MNDLNDFLK & TISLLFIFFLLL & SLPTVAEA & Increase hydrophobicity \\
M7 & MNDLNDFLK & TISLGFIFFLLL & SLPTVAEA & Introduce G-turn motif \\
M11 & MNDLNDFLK & TISLSFIFGLLL & SLPTVAEA & Decrease hydrophobicity and introduce G-turn motif \\
M5 & MNDLNDFLK & TISLSFGFFLLL & SLPTVAEA & Decrease hydrophobicity and introduce G-turn motif \\
M2 & MNDLNDFLK & TISLSFIFFLLL & SLPTVSEA & Alter signal peptidase recognition affinity \\
M4 & MNDLNDFLK & TISLSFIFFLLL & SLPTVGEA & Alter signal peptidase recognition affinity \\
\hline
\end{tabular}

Each mutated amino acid sequence is denoted with a bold letter.

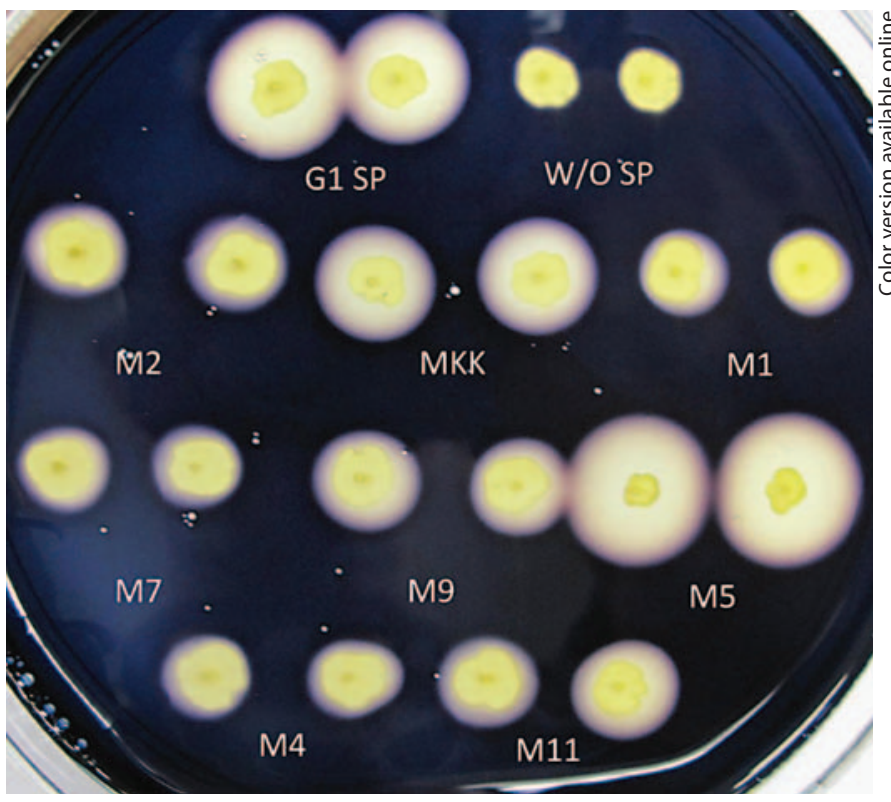

Fig. 1. Extracellular secretion of CGTase from Bacillus sp. G1 using a wild-type CGTase SP (G1) and the mutant variants expressed in E. coli. Halo zones were not observed from strains lacking the SP. The formation of halo zones surrounding colonies was induced by growing the cells at $30^{\circ} \mathrm{C}$ on solid LB-starch plates containing $0.5 \%$ (w/v) soluble starch, $0.5 \mathrm{~mm}$ IPTG and $50 \mu \mathrm{g} / \mathrm{ml}$ ampicillin. Halo zones were revealed after treatment with iodine solution.

in this study. To improve the secretion of this CGTase, mutations were performed on the wild-type SP.

Site-directed mutagenesis was used to construct a series of mutations in the SP region of the CGTase gene. The effects of amino acid alterations on the secretory performance of the mutants were evaluated. The amino acid sequences of mutants and their predicted effects are shown in table 4 . Halo zones exhibited by the extracellular secretion of recombinant CGTase by different mutant SPs were screened using starch-containing LB plates. As shown in figure 1, different variants of mutant SPs exhibited different levels of secreted CGTase.

\section{Effects of Mutations in Different Regions of the SP on} Secretion Level

Gram-negative bacteria such as E. coli consist of three different compartments: cytoplasm, periplasm and extracellular space. The secretion of a variety of proteins to these compartments is mediated through their inner and outer membranes. Mutation of the SP will affect the rate of translocation of the target protein through these membranes and finally to each of the compartments.

The effects of the mutant SPs on the secretion of CGTase to different $E$. coli compartments are shown in figure 2. The change of the n-region's net charge from -2 (G1) to -1 (M1) or +1 (MKK) yielded a lower level of CGTase secretion compared to the E. coli host harboring the wild-type GI SP. The importance of the n-region's positive charge is uncertain. The positive charge of the $\mathrm{n}$-region is essential for recognition by translocase, SecA, to initiate protein translocation and also to interact with the negatively charged lipids at the cell membrane [Akita et al., 1990]. In addition, the n-region's positive charge density increases the secretory efficiency of $E$. coli alkaline phosphatase SP [Izard et al., 1996]. Furthermore, the introduction of a positive charge in the form of arginine residues might also result in a higher susceptibility of the mutant SP to degradation by SP peptidase (SPPase) [Matsumi et al., 2005]. In contrast, Morioka-Fujimoto et al. [1991] showed that the increase of the n-region's positive 
charge of the enterotoxin SP did not affect the secretion of recombinant human epidermal growth factor. For the mutants BM1 and MKK, reductions of 68 and $15 \%$ were observed for secreted CGTase into the periplasmic space, respectively.

Interestingly, the introduction of a G-turn motif or helix breaker in the h-region resulted in a significant increase in CGTase transported across the cytoplasmic membrane, as exhibited by mutant M11 and M5. Figure 2 shows the significant increases of recombinant CGTase secreted to the periplasmic space of the E. coli host harboring the mutated SP of mutant M11 or M5 as compared to the wild-type SP (G1) after $1 \mathrm{~h}$ post-induction time. Substitution of phenylalanine at position -12 to glycine (M11) resulted in a $110 \%$ increase of periplasmic CGTase, while substitution of isoleucine at position -14 to glycine (M5) resulted in a $140 \%$ increase of periplasmic CGTase compared to wild-type SP. However, introduction of a Gturn or helix breaker at position -16 (M7) only yielded a wild-type level of periplasmic secretion of CGTase. Although both mutants (M11 and M5) showed significant increases in the overall secretion of CGTase, different levels of extracellular CGTase were observed.

Mutant M5 conferred an increase of $94 \%$ in extracellular CGTase compared to wild-type SP, while M11 yielded similar CGTase extracellular secretion to wild-type. However, a significant reduction in extracellular CGTase (65\% of wild-type G1 SP) was observed using mutant M7. The high levels of extracellular secretion shown in previous studies [Shokri et al., 2003] could be due to cell leakage or lysis caused by pressure build-ups as the transported proteins accumulated in the periplasmic space. From the constructed sequence data of the E. coli N-terminal SP, about $47 \%$ of the bacterial dataset exhibit a consensus G-turn motif at the h-region (data not shown). This suggests that the motif contain an important structural recognition domain for efficient protein transport. Indeed, our findings of enhanced periplasmic secretion using the mutant M11 SP and M5 SP confirm the importance of the G-turn motif in protein secretion and translocation.

In this study, the amount of secreted CGTase was higher in M5 compared to M11; this could have been due to different locations of the G-turn added to the G1 SP, as shown by Lemberg and Martoglio [2002]. Secretion is favored by G-turn motifs at the center of the h-region, as in the case of mutant M5 compared to M11. A glycine residue in the middle of the h-region could be involved in the proteolysis of SP, which is consistent with the previous finding that the helix-breaking residue in the center of the h-region is recognized by a SPPase [Lemberg et al.,

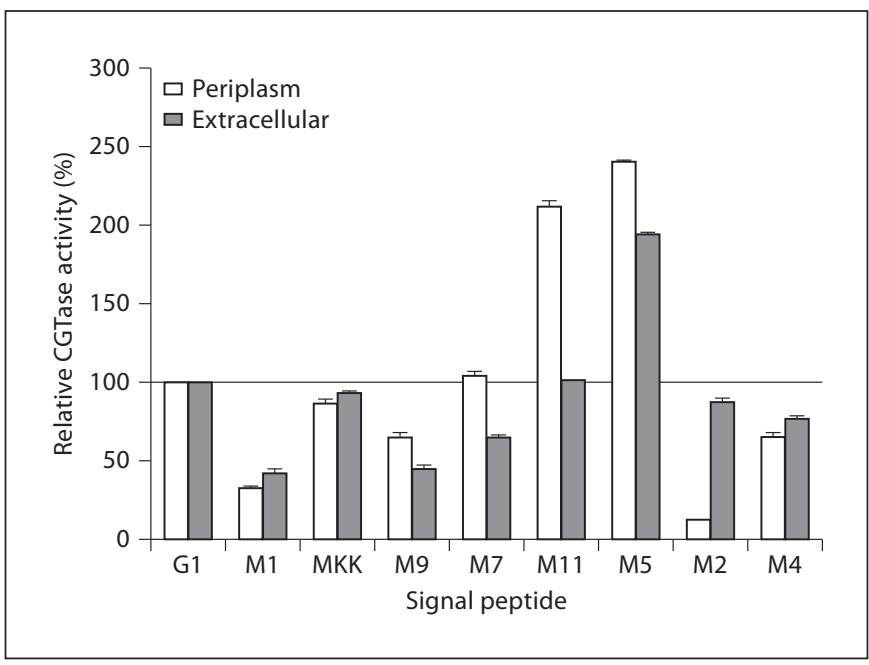

Fig. 2. Effects of mutant SPs on the secretion of CGTase to the periplasmic and extracellular spaces. Samples from the periplasmic and extracellular fractions were taken at 1 and $24 \mathrm{~h}$ post-induction, respectively. Secretory activity was calculated relative to wild-type (G1) activity.

2001]. SPPase is essential in digesting the cleaved SP [Zwizinski and Wickner, 1980] to avoid its accumulation at the inner membrane, which can cause cell death due to membrane rapture. Studies on the requirement of a helix break for intramembrane cleavage by SPPase revealed that the lack of a helix-breaking residue in the h-region of the SP prevents its processing [Lemberg and Martoglio, 2002]. Our study shows that the helix breaker is not only important in protein secretion in E. coli, but also has significant effects on protein translocation when fused to the SP from Bacillus sp., which lacks helix-breaking amino acids, to function as heterologous SP. In the case of GspB SP of Streptococcus gordonii, a Gram-positive bacterium, the presence of glycine residues in the hydrophobic core is necessary for the export of proteins via the accessory Sec pathway [Bensing et al., 2007]. Replacement of the h-region glycine residue with helix-promoting residues leads to a decrease in the efficiency of SecA2-dependent transport of the pre-protein and a simultaneous increase in SecA2-independent translocation.

On the other hand, increasing the hydrophobicity of the h-region by the addition of a leucine residue is a possible strategy to promote recombinant protein secretion, as demonstrated for the expression of alkaline phosphatase in E. coli [Izard et al., 1996] and human interleukin-2 in Bacillus brevis [Takimura et al., 1997]. In line with this, we increased the hydrophobicity of G1 SP by substituting 


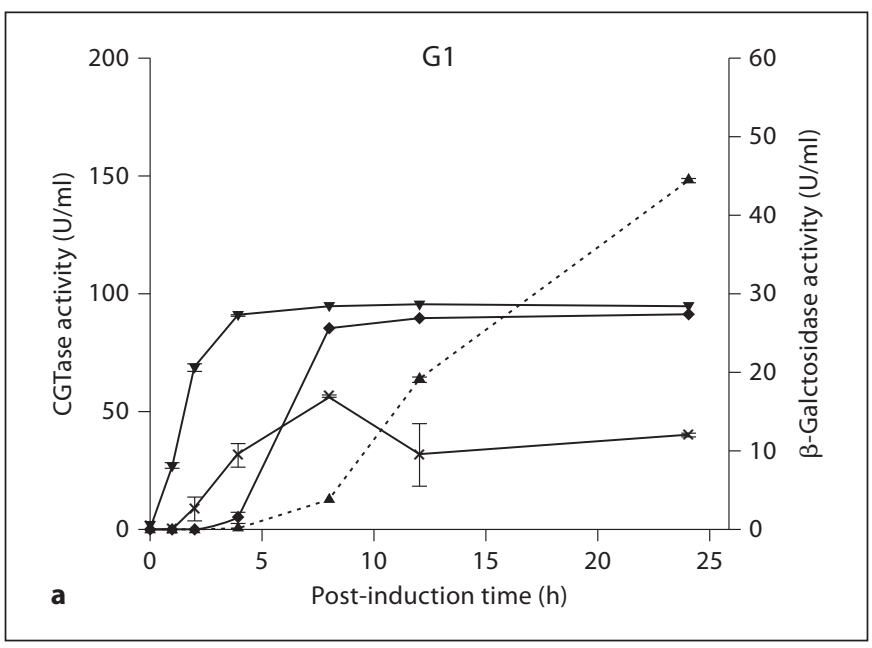

Fig. 3. Secretion profiles. Detection of CGTase activity in the different cell compartments of $E$. coli BL21(DE3) using the wild-type SP (G1) (a), PelB SP (b) and M5 mutant SP (c). The culture was grown at $37^{\circ} \mathrm{C}$ until $\mathrm{OD}_{600 \mathrm{~nm}}$ reached 0.7 , and it was then induced with $1 \mathrm{mM}$ IPTG and incubated at $30^{\circ} \mathrm{C}$ for another $48 \mathrm{~h}$. All experiments were evaluated under identical conditions and performed in triplicate. - CGTase activity in the extracellular medium; $\boldsymbol{\nabla}$ = periplasm; $\times=$ cytoplasm. The $\beta$-galactosidase activity detected in the culture medium $(\boldsymbol{\Delta})$ was used as an indicator of cell lysis.

leucine at position -16 (M9). However, the resulting mutant exhibited decreased CGTase secretion. A similar observation by Rusch et al. [2002] demonstrated that increasing hydrophobicity has only a marginal effect on the transport of alkaline phosphatase. In addition, our study shows that a decrease in hydrophobicity due to the addition of a G-turn, as indicated in mutants M11 and M5, led to increased secretion of recombinant CGTase into the periplasmic space. We believe that the role of h-region hydrophobicity in regulating the secretory pathway is not clear and requires more detailed investigation.

The activity of the signal peptidase to cleave SP is affected by the residues at positions -1 and -3 relative to the start of the mature region [Jain et al., 1994]. Low secretion of CGTase to the periplasm and extracellular space was observed when the signal peptidase recognition affinity at position -3 was substituted by small neutral side chain
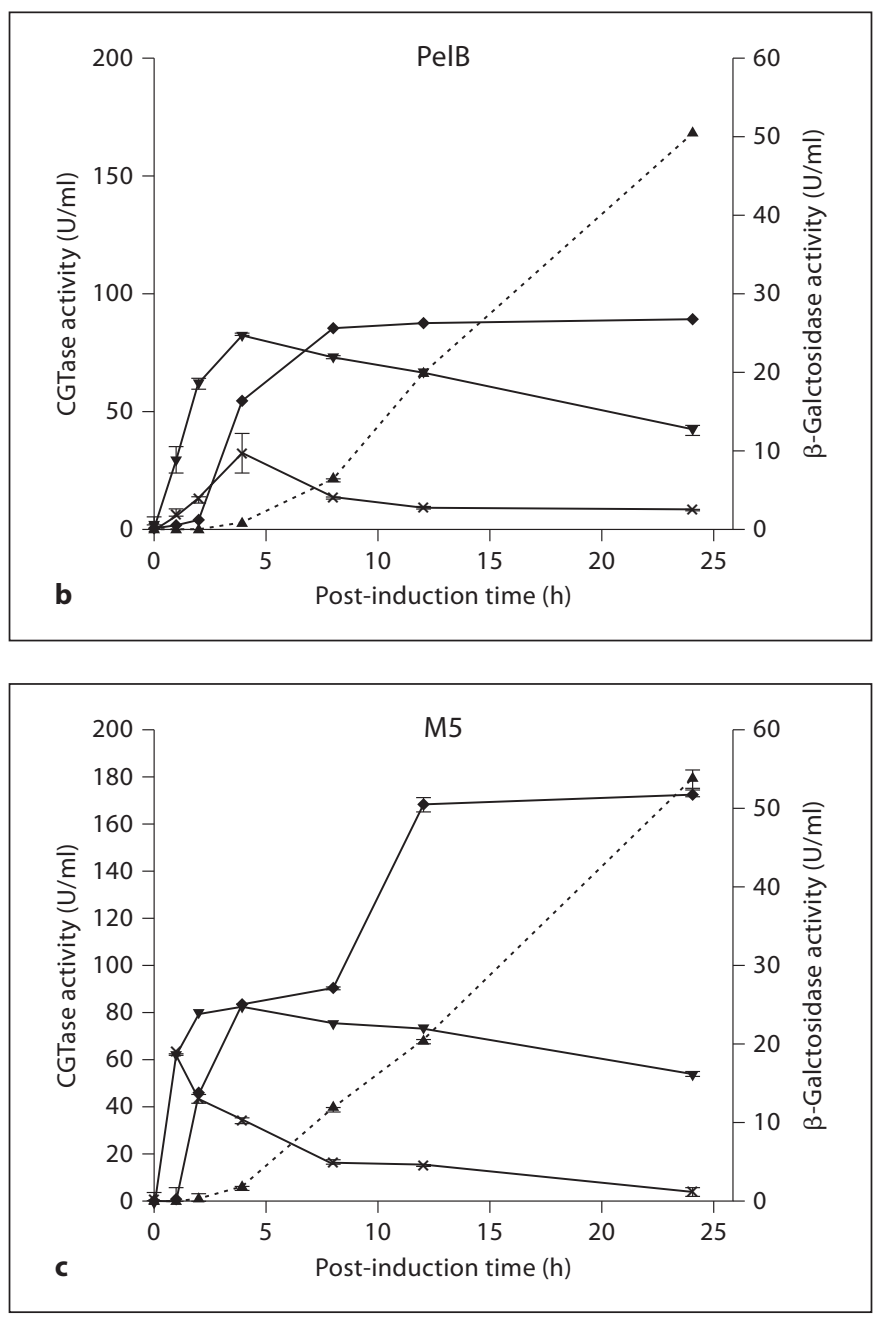

amino acids, as demonstrated by mutants M2 and M4. This result is consistent with previous studies that suggest that the cleavage of SP is important for target protein translocation. Most pre-secretory proteins are cleaved 5-7 residues downstream from the h-domain by the major signal peptidase, such as in the case LepB protein in E. coli [Pugsley, 1993].

Comparison of the secretory profiles of CGTase using PelB, G1 and M5 SPs and their effects on cell viability and protein solubility.

PelB SP is one of the most widely used targeting signals to direct target proteins to the periplasmic space in E. coli. Therefore, in this study, we compared and evaluated the effectiveness of our mutant SP (BM5 SP), wild-type G1 SP and PelB SP in the translocation of recombinant CGTase in batch culture and their effects on cell viability and CGTase solubility. As shown in figure 3a, wild-type G1 
SP led to the transport and accumulation of CGTase into the periplasm until $4 \mathrm{~h}$ post-induction $(91 \mathrm{U} / \mathrm{ml})$, when no further increase of CGTase was detected. Subsequently, extracellular CGTase activity steadily increased from $2 \mathrm{~h}$ post-induction until it reached a plateau at $8 \mathrm{~h}$ postinduction $(86 \mathrm{U} / \mathrm{ml})$. Concomitantly, the detection of a cytoplasmic enzyme, $\beta$-galactosidase, in the extracellular medium could have been due to the accumulation of the target protein in the cytoplasm and periplasmic space, leading to increased osmotic pressure in the host cell, and caused a rupture of the outer membrane, thereby allowing the release of proteins into the culture medium [Hasenwinkle et al., 1997]. On the other hand, the profile of CGTase using PelB SP was similar to G1 SP, except that it showed a lower level of soluble cytoplasmic CGTase (fig. 3a, b), with a $73.54 \%$ reduction in solubility at $12 \mathrm{~h}$ post-induction. Previous attempts to express CGTase in E. coli hosts have led to the formation of inclusion bodies [Kweon et al., 2004]. Inefficient transportation of target recombinant proteins to the periplasmic space can lead to accumulation of the protein and cause inclusion body formation [Baneyx and Mujacic, 2004], which could have been the case in the secretion of CGTase using PelB in this study.

Interestingly, M5 SP showed a significant increase in extracellular CGTase ( $\sim 170 \mathrm{U} / \mathrm{ml}$ at $12 \mathrm{~h}$ post-induction), which was about 1.9-fold higher in yield compared to wild-type G1 and PelB SP. Most importantly, this increase in extracellular CGTase occurred with a similar amount of cytoplasmic $\beta$-galactosidase ( $6.5 \%$ increased) released into the culture medium. As mentioned above, M5 showed a high level of secreted CGTase but less cell lysis (based on $\beta$-galactosidase activity compared to PelB and wild-type G1 SP). This observation could have been due to efficient removal of the cleaved SP by SPPase, thus preventing the destruction of membrane integrity caused by SP accumulation in the inner membrane. Our results suggest the potential use of this mutant SP for extracellular protein expression. The profile in figure 3 also shows that mutant M5 SP gave the highest soluble cytoplasmic CGTase at less than $2 \mathrm{~h}$ post-induction among the tested SPs. A subsequent decrease in cytoplasmic CGTase activity at $2 \mathrm{~h}$ post-induction (as shown in fig. $3 \mathrm{c}$ ) was accompanied by increases in periplasmic and extracellular CGTase. This finding indicates that M5 SP has the highest efficiency to translocate CGTase into the periplasmic space and subsequently into the culture medium within $2 \mathrm{~h}$ of induction compared to PelB and wild-type G1 SP. This rapid translocation may have mitigated the formation of inclusion bodies resulting from the accumulation

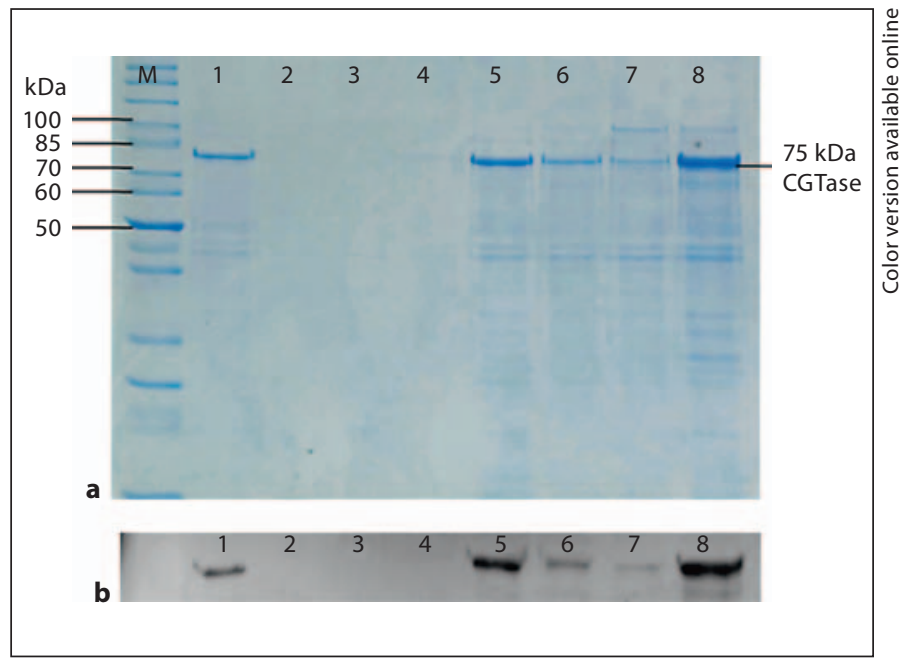

Fig. 4. Solubility comparison of recombinant CGTase in the insoluble fraction of different expression plasmids constructed in this study. a SDS-PAGE analysis of recombinant CGTase in insoluble fractions at $1 \mathrm{~h}$ (lanes $1-4)$ and $12 \mathrm{~h}$ (lanes 5-8) post-induction that were taken from recombinant $E$. coli grown in LB medium. b Western blot analysis of recombinant CGTase in the insoluble fractions corresponding to the SDS-PAGE analysis. Lane $M$, protein size marker; lanes 1 and 5, recombinant CGTase lacking SP; lanes 2 and 6, CGTase fused with G1 SP; lanes 3 and 7, CGTase fused with M5 SP; lanes 4 and 8, CGTase fused with PelB SP.

of proteins inside the cytoplasm that normally occurs in the E. coli host during CGTase expression.

The formation of inclusion bodies of CGTase when expressed in E. coli is of major concern [Jemli et al., 2008]. High expression of CGTase might cause a sequestration of components involved in incorrect protein folding and secretory pathway targeting, such as DnaK and SecB, resulting in the formation of inclusion bodies [Fang et al., 2010]. We compared the insoluble fractions of E. coli harboring plasmids with an SP from wild-type G1, PelB or mutant M5 using SDS-PAGE and Western blotting. As shown in figure 4, no significant formation of inclusion bodies was detected for the CGTase fused to the M5 mutant $\mathrm{SP}$ at $12 \mathrm{~h}$ post-induction. However, a clear band representing inclusion bodies were detected for CGTase fused with the PelB SP and lacking SP. According to Baneyx [1999], SPs can influence secondary and tertiary structure formation in the mature region of the secretory protein, which can affect molecular chaperon recognition and thus protein folding. Our results clearly show the advantages of using M5 in decreasing inclusion bodies formation compared to PelB. 


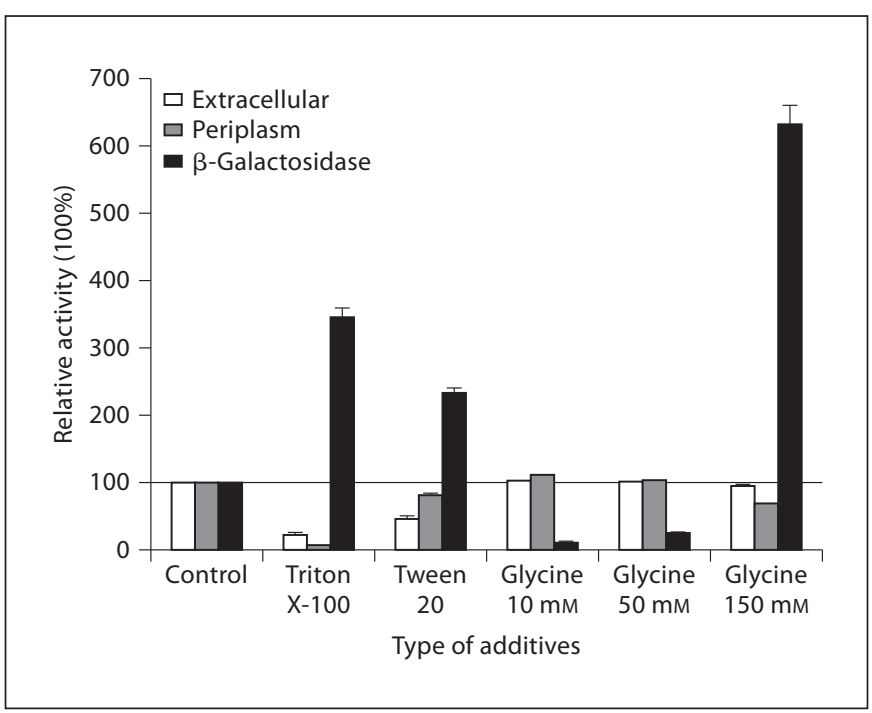

Fig. 5. Effects of chemical additives on the secretory production of CGTase and cell viability of recombinant E. coli at $1 \mathrm{~h}$ postinduction. Samples were taken $12 \mathrm{~h}$ post-induction.

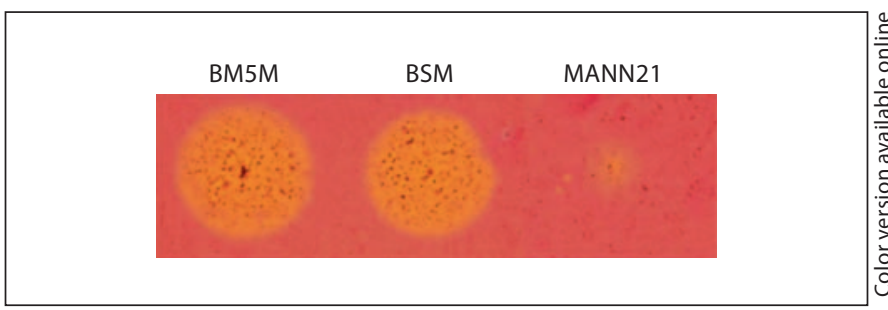

Fig. 6. Halo formation by recombinant mannosidase produced by E. coli strain BL21 (DE3) harboring BM5M (plasmid containing M5 SP), BSM (plasmid containing G1 SP) or MANN21 (lacking a SP). Each recombinant cell population was grown on LB plates containing $1 \%$ locust bean gum at $37^{\circ} \mathrm{C}$ for $16 \mathrm{~h}$. Plates were stained with Congo red solution (1\%, w/v) and destained with $1 \mathrm{M}$ $\mathrm{NaCl}$.

\section{Reduction of Cell Lysis}

As described above, the use of M5 mutant SP, although it led to an increase in the CGTase translocation rate, still caused a high rate of cell lysis. An addition of additives can be an effective way to release enzyme into the extracellular space, which reduce pressure build in the periplasmic space and eventually reduce cell lysis. A number of chemical additives, including glycine $(150,50$, $10 \mathrm{~mm})$, Tween $20(2 \%, \mathrm{v} / \mathrm{v})$ and Triton X-100 (2\%, v/v), were added to the cell culture harboring the M5 SP at $1 \mathrm{~h}$ post-induction. However, we observed an interesting result, as shown in figure 5 . Instead of an increase in the release of CGTase into the culture medium, we observed reduced cell lysis along with comparable or reduced amounts of CGTase secreted into the medium. Based on $\beta$-galactosidase release to the extracellular space, supplementation of Triton X-100 and Tween 20 resulted in a $\sim 2$ - to 3.5-fold increase in cell lysis but yielded a significant reduction in extracellular and periplasmic CGTase (8-82\% compared to no additive or control). Addition of glycine, however, did not significantly affect transport of CGTase across the inner and outer membranes. Lower concentrations of glycine ( 10 and $50 \mathrm{mM}$, or equal to 0.08 and $0.38 \%$, respectively) appeared to maintain host cell viability (based on $\beta$-galactosidase activity), while a higher concentration of glycine $(150 \mathrm{~mm}$ or $1.13 \%)$ decreased cell viability, as judged from the extracellular $\beta$ galactosidase released. Li et al. [2010] showed that addition of glycine at a concentration of $1 \%$ (at $0 \mathrm{~h}$ post-induction) results in increased release of recombinant $\alpha$-CGTase, which is followed by a significant increase in cell lysis. Furthermore, they also showed that delaying glycine supplementation can mitigate cell growth impairment. Nevertheless, in our study, we observed that the use of glycine at less than $1 \%$ at $1 \mathrm{~h}$ post-induction improved cell viability (fig. 5).

\section{Secretory Expression of an Additional Protein}

By using the M5 SP plus supplementation of glycine $(0.08 \%, w / v)$, we tested the extracellular production of another protein. An endomannosidase from Aspergillus flavus was chosen as a candidate to evaluate the effectiveness of our system. Cultivation of the respective recombinant $E$. coli cells onto LB-mannan agar plates indicated that mannosidase secretion depended on the SP (fig. 6). As shown in figure 7, the supernatant and periplasmic mannosidase activities of M5-mannosidase were significantly higher than recombinant mannosidase fused with wild-type G1 SP. At least a 1.4-fold increase in extracellular production of mannosidase was obtained by the use of the M5 SP. The SPs induced accumulation of mannosidase in the periplasmic space, followed by gradual secretion into the extracellular medium. Maximum extracellular mannosidase activity was achieved at $12 \mathrm{~h}$ post-induction for M5 SP (77.98 $\mathrm{U} / \mathrm{ml})$ and wild-type G1 SP $(14.26 \mathrm{U} / \mathrm{ml})$. The intracellular mannosidase activity was similar for both SPs, suggesting the effectiveness of M5 SP in protein targeting. These results suggest that M5 SP has the potential to efficiently direct secretion of not only CGTase but other proteins as well, as demonstrated by our findings on mannosidase secretion. 


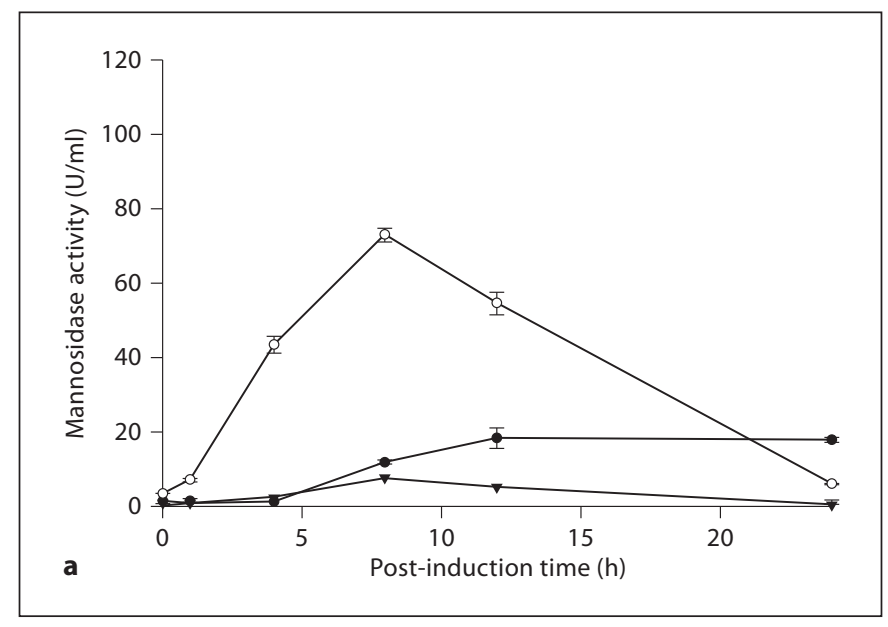

Fig. 7. Secretion profiles. The detection of mannosidase activity in different cell compartments of E. coli BL21 (DE3) using G1 SP (a) or M5 SP (b). The culture was grown at $37^{\circ} \mathrm{C}$ until $\mathrm{OD}_{600 \mathrm{~nm}}$ reached 0.8 , and it was then induced with $0.01 \mathrm{mM}$ IPTG and in-

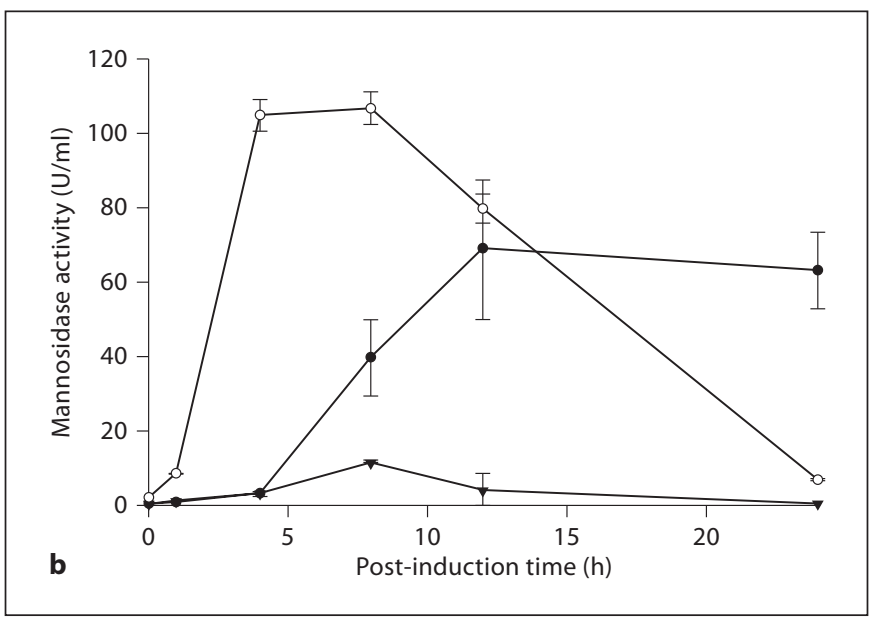

cubated at $30^{\circ} \mathrm{C}$ for another $48 \mathrm{~h}$. All experiments were evaluated under identical conditions and carried out in triplicate. Mannosidase activity is depicted in the extracellular medium $(\bullet)$, periplasm $(\bigcirc)$, and cytoplasm $(\boldsymbol{\nabla})$.

\section{Conclusion}

Our findings clearly demonstrate that modifying the amino acid composition of a SP can improve the secretion of recombinant CGTase to the periplasmic and, eventually, the extracellular space of E. coli. The use of a heterologous SP from Bacillus sp. works well in an E. coli system. It is interesting to note that substitution to a G-turn in our case had a significant impact on the secretion level of CGTase. Our results also show the roles played by mutated SPs in CGTase solubility. Finally, we believe the combination of molecular and medium design approach- es can lead to improvements in protein secretion and cell viability for protein production. The ability to secrete target proteins in large quantities extracellularly with minimum cell lysis should provide enormous potential for industrial and clinical applications.

\section{Acknowledgement}

This project was supported by the Genomics and Molecular Biology Initiatives Programme of the Malaysia Genome Institute, Ministry of Science, Technology and Innovation Malaysia (Project No. 07-05-MGI-GMB011).

\section{References}

Akita M, Sasaki S, Matsuyama S, Mizushima S: Seca interacts with secretory proteins by recognizing the positive charge at the amino terminus of the signal peptide in Escherichia coli. J Biol Chem 1990;265:8164-8169.

-Baneyx F: Recombinant protein expression in Escherichia coli. Curr Opin Biotechnol 1999. 10:411-421.

Baneyx F, Mujacic M: Recombinant protein folding and misfolding in Escherichia coli. Nat Biotechnol 2004;22:1399-1408.

Bensing BA, Siboo IR, Sullam PM: Glycine residues in the hydrophobic core of the GSPB signal sequence route export toward the accessory sec pathway. J Bacteriol 2007;189: 3846-3854.
Fang N, Zhong C-Q, Liang X, Tang X-F, Tang B: Improvement of extracellular production of a thermophilic subtilase expressed in Escherichia coli by random mutagenesis of its $\mathrm{N}$ terminal propeptide. Appl Microbiol Biotechnol 2010;85:1473-1481.

Fu X-Y: Extracellular accumulation of recombinant protein by Escherichia coli in a defined medium. Appl Microbiol Biotechnol 2010; 88:75-86.

Fu ZB, Ng KL, Lam TL, Wong WKR: Cell death caused by hyper-expression of a secretory exoglucanase in Escherichia coli. Protein Expr Purif 2005;42:67-77.
Hasenwinkle D, Jervis E, Kops O, Liu C, Lesnicki G, Haynes CA, Kilburn DG: Very high-level production and export in Escherichia coli of a cellulose binding domain for use in a generic secretion-affinity fusion system. Biotechnol Bioeng 1997;55:854-863.

Ibrahim HM, Yusoff WMW, Hamid AA, Illias RM, Omer O: Optimization of the process conditions for cyclodextrin glucanotransferase production using response surface methodology. Asian J Microbiol Biotechnol Environ Sci 2003;5:297-300.

Izard JW, Rusch SL, Kendall DA: The amino-terminal charge and core region hydrophobicity interdependently contribute to the function of signal sequences. J Biol Chem 1996; 271:21579-21582. 
Jain RG, Rusch SL, Kendall DA: Signal peptide cleavage regions. Functional limits on length and topological implications. J Biol Chem 1994;269:16305-16310.

Jemli S, Messaoud EB, Mabrouk SB, Bejar S: The cyclodextrin glycosyltransferase of Paenibacillus pabuli US132 strain: molecular characterization and overproduction of the recombinant enzyme. J Biomed Biotechnol 2008; 2008:692573.

-Jeong KJ, Lee SY: Secretory production of human leptin in Escherichia coli. Biotechnol Bioeng 2000;67:398-407.

Khokhlova OV, Nesmeyanova MA: Interaction of $\mathrm{SecB}$ and $\mathrm{Sec} A$ with the $\mathrm{N}$-terminal region of mature alkaline phosphatase on its secretion in Escherichia coli. Mol Biol 2003;37: 712-718.

Kweon D-H, Kim S-G, Seo J-H: Purification and refolding of cyclodextrin glycosyltransferase expressed Escherichia coli. J Incl Phenom Macrocycl Chem 2004;50:37-41.

Laemmli UK: Cleavage of structural proteins during the assembly of the head of bacteriophage T4. Nature 1970;227:680-685.

Lemberg MK, Bland FA, Weihofen A, Braud VM, Martoglio B: Intramembrane proteolysis of signal peptides: an essential step in the generation of HLA-E epitopes. J Immunol 2001; 167:6441-6446.

Lemberg MK, Martoglio B: Requirements for signal peptide peptidase-catalyzed intramembrane proteolysis. Mol Cell 2002;10: 735-744.

-Li Z, Gu Z, Wang M, Du G, Wu J, Chen J: Delayed supplementation of glycine enhances extracellular secretion of the recombinant $\alpha$-cyclodextrin glycosyltransferase in Escherichia coli. Appl Microbiol Biotechnol 2010;85: 553-561.
Matsumi R, Atomi H, Imanaka T: Biochemical properties of a putative signal peptide peptidase from the hyperthermophilic arcaheon Thermococcus kodakaraensis KOD1. J Biotechnol 2005;187:7072-7080.

-Morioka-Fujimoto K, Marumotot R, Fukuda T: Modified enterotoxin signal sequences increase secretion level of the recombinant human epidermal growth factor in Escherichia coli. J Biol Chem 1991;266:1728-1732.

Nakamura K, Furusato T, Shiroza T, Yamane K: Stable hyperproduction of Escherichia coli $\beta$ lactamase by Bacillus subtilis grown on a 0.5 M succinate-medium using a $b$. Subtilis $\alpha$ amylase secretion vector. Biochem Biophys Res Commun 1985;128:601-606.

-Nesmeyanova MA, Karamyshev AL, Karamyshev ZN, Kalinin AE, Ksenzenko VN, Kajava AV: Positively charge lysine at the N-terminus of the signal peptide of the Escherichia coli alkaline phosphatase provides the secretion efficiency and is involved in the interaction with anionic phospholipids. FEBS Lett 1997;403:203-207.

Ni Y, Chen R: Extracellular recombinant protein production from Escherichia coli. Biotechnol Lett 2009;31:1705-1714.

Ong RM, Goh KM, Mahadi NM, Hassan O, Rahman RNZRA, Illias RM: Cloning, extracellular expression and characterization of a predominant $\beta$-cgtase from Bacillus sp. G1 in E. coli. J Ind Microbiol Biotechnol 2008; 35:1705-1714.

Pugsley A, Francetic O: Protein secretion in Escherichia coli K-12: dead or alive? Cell Mol Life Sci 1998;54:347-352.

Pugsley AP: The complete general secretory pathway in Gram-negative bacteria. Microbiol Mol Biol Rev 1993;57:50-108.
Rusch S, Mascolo C, Kebir M, Kendall D: Juxtaposition of signal-peptide charge and core region hydrophobicity is critical for functional signal peptides. Arch Microbiol 2002; 178:306-310.

Sanchez L, Ayala M, Freyre F, Pedroso I, Bell H, Falcon V, Gavilondo JV: High cytoplasmic expression in E. coli, purification, and in vitro refolding of a single chain $\mathrm{Fv}$ antibody fragment against the hepatitis B surface antigen. J Biotechnol 1999;72:13-20.

Shokri A, Sandén AM, Larsson G: Growth ratedependent changes in Escherichia coli membrane structure and protein leakage. Appl Microbiol Biotechnol 2002;58:386-392.

-Shokri A, Sandén AM, Larsson G: Cell and process design for targeting of recombinant protein into the culture medium of Escherichia coli. Appl Microbiol Biotechnol 2003;60: 654-664.

Takimura Y, Kato M, Ohta T, Yamagata H, Udaka S: Secretion of human interleukin-2 in biologically active form by Bacillus brevis directly into culture medium. Biosci Biotech Biochem 1997;61:1858-1861.

Von Heijne G, Abrahmsen L: Species-specific variation in signal peptide design. Implications for protein secretion in foreign hosts. FEBS Lett 1989;244:439-446.

Yamabhai M, Emrat S, Sukasem S, Pesatcha P, Jaruseranee N, Buranabanyat B: Secretion of recombinant Bacillus hydrolytic enzymes using Escherichia coli expression systems. J Biotechnol 2008;133:50-57.

Yoon SH, Kim SK, Kim JF: Secretory production of recombinant proteins in Escherichia coli. Biotechnology 2010;4:23-29.

Zwizinski C, Wickner W: Purification and characterization of leader (signal) peptidase from Escherichia coli. J Biol Chem 1980;255:79737977. 